\title{
Arbor
}

\section{En el espíritu de la ilustración}

\section{Joaquín $M^{a}$ Córdoba}

Arbor CLXXX, 711-712 (Marzo-Abril 2005), 699-706 pp.

En el museo del Carnavalet se conserva un curioso óleo, firmado por Pierre-Denis Martín, que representa un cortejo del embajador turco en París hacia 1721. El cuadro es todo un símbolo de la realidad de Europa y el Oriente cercano a comienzos del siglo XVIII: la Francia de la Regencia parece hegemónica, Turquía busca su alianza, y trajes, protocolos y cultura se han hecho recargados, graciosos, elegantes. Verdaderamente se estaban viviendo los inicios de un mundo radicalmente nuevo, que a lo largo del siglo iba a cambiar todavía más, a medida que la Ilustración se fuera convirtiendo en el espíritu de la época.

A comienzos de siglo, quizás por causa de las guerras borbónicas y las necesidades internas de las monarquías europeas, los viajes a Oriente se hicieron más escasos, y entre su literatura apenas destacan libros especiales, salvo una obra de excepción. Cuando en 1721 el embajador turco presentaba sus respetos al Regente, en Francia y Europa gozaban de gran fama las versiones francesas de un viaje realizado a Oriente entre 1701 y 1708 por un artista holandés, llamado Cornelis de Bruijn. Dichas ediciones incluían magníficas láminas grabadas sobre las ruinas de Persépolis, las primeras hechas con el realismo suficiente como para dar una información veraz del conjunto y los detalles del legendario complejo. Y si su largo viaje desde Holanda a Rusia, Mar Caspio, Irán, India y Ceylán, con igual ruta a la vuelta, proporcionó un relato ameno y atento a los datos e interpretaciones de sus antecesores -demostrando por cierto una notable erudición ${ }^{1}-$, Cornelis de Bruijn era muy consciente de que su estancia en Persépolis, la descripción que de ella hizo y las láminas precisas que de sus ruinas realizó, constituían lo más importante de su experiencia y una de las más valiosas aportaciones al redescubrimiento del pasado oriental ${ }^{2}$. Tras él, pocos viajeros notables surcaron Oriente, pero en la segunda mitad de la centuria, gentes imbuidas del espíritu de 
las Luces navegaron sus mares y volvieron a transitar por sus pistas. Justo entonces entrarían en esta historia con méritos propios y obras singulares, los dos mejores viajeros españoles del siglo, Gabriel de Aristizábal y Federico Gravina.

A comienzos de siglo, gracias sin duda a la debilidad que mostraba, el Oriente cercano que era Turquía empezó a ser visto con una cierta simpatía. Hacía mucho tiempo que los libros de viaje e historia describían el imperio otomano y los países del Levante, pero el interés preciso por las costumbres y valores sería cosa del XVIII, lo mismo que el verdadero descubrimiento literario de Oriente vendría de mano de los doce volúmenes de la traducción francesa de Las mil y una noches, publicados por el orientalista Antoine Gallan entre 1704 y $1717^{3}$. Aunque muy morigerada, su versión ayudó a despertar ciertas ensoñaciones de sensualidad y lujo que se suponían propias de Oriente. Los llamados pintores del Bósforo, como Jean-Baptiste van Mour, que en 1699 acompañó al embajador francés Charles de Ferriol a Istanbul, donde decidió quedarse a vivir hasta su muerte (1737), fueron facilitando cuadros e imágenes que representaban sobre todo escenas del protocolo diplomático, pero también ambientes y rasgos de la vida cotidiana de los turcos, en lienzos llenos de vivacidad ${ }^{4}$. Pero mucho más impacto alcanzaría una colección de dibujos de van Mour, que con el título de Recueil de Cent Estampes, représentant differentes Nations du Levant tirées sur les Tableaux peints d'après Nature en 1707 et 1708, publicaría en La Haya el embajador de Ferriol a su vuelta a Europa. Esta colección de láminas sería decisiva en la difusión de una moda turquesca, que pronto afectaría a todas las artes como la pintura, la cerámica y porcelana, la música e incluso la literatura ${ }^{5}$. Precisamente por esos años, Van Mour pintaría en uno de sus típicos cuadros, a la esposa del embajador británico, Lady Mary Wortley Montagu' autora de una colección de cartas admirables, que describen su viaje y las impresiones vividas en Turquía entre 1716 y 1718. Lady Mary debió guardar una copia de las cartas enviadas, que luego iba pasando a unos álbumes, al tiempo que corregía y mejoraba el texto, con la probable idea de publicarlas algún día. Pero lo cierto es que hasta 1763 , a poco de su muerte, no verían la luz, si bien desde entonces gozarían de notable fama $^{7}$, ya que por su condición femenina, la esposa del embajador había tenido acceso a ambientes cerrados por completo a los hombres.

Durante la primera mitad del siglo, la Europa de Luis XV (1723-1774) se va convirtiendo en la del lujo y el derroche de las fiestas del Parc aux Cerfs. También entonces, junto al gusto por las sedas, los costosos vestidos, las porcelanas y las joyas aparecieron los primeros juicios críticos, 
como las Cartas Persas, de Montesquieu ${ }^{8}$, con las que la Ilustración temprana entra en escena criticando las injustas condiciones colectivas y sociales $^{9}$. El recurso de escoger a unos viajeros persas llamados Rica y Usbek, como relatores críticos de cuanto van viendo de la sociedad francesa, no deja de ser irónico pues desvela "todo el absurdo y toda la autocomplacencia de una sociedad segura de sí misma y de la bondad de sus costumbres» ${ }^{10}$, pero al mismo tiempo suponen una manifestación más del «juego» orientalizante.

Lo turco -lo oriental- empieza a ser moda. Muchos miembros de la nobleza gustaron de hacerse retratos vestidos a la turca, como la condesa Maria Teresa Kollonitz, la archiduquesa Luisa von Schleswig-Holstein-Sonderburg-Augustenburg la misma emperatriz María Teresa de Austria y tantos otros, con los que participan alegres en fiestas y reuniones ${ }^{11}$. La moda se extendió fácilmente a la decoración de interiores, como los "cabinets turcs» de los años setenta -entre los que destaca el «Boudoir turc» de María Antonieta ${ }^{12}$ - y a las artes decorativas, particularmente a la porcelana. En la fábrica sajona de Meissen, en el curso de los años cuarenta y cincuenta los maestros Johann Joachin Kändler, Peter Reinicke, Johann Friedrich Eberlein y otros empezaron a modelar preciosas figuritas de porcelana, que representaban nobles y tipos turcos, damas o servidores ${ }^{13}$. Otras manufacturas europeas repitieron y ampliaron las series de tipos turcos o servicios de mesa, y unos y otros alcanzaron gran aceptación en Europa. Su belleza y luminosidad se me antoja perfecto acompañamiento de la novela filosófica del Zadig de Voltaire (1747), que por cierto se ambienta en una Babilonia imaginaria, en donde el ingenuo termina alcanzando la "sabiduría oriental de la aceptación»" ${ }^{14}$. Y claro está, de la música. Durante el siglo XVIII, los turcos poblaron también las escenas y las representaciones musicales europeas ${ }^{15}$, aunque la obra más famosa sea hoy El rapto del serrallo, de Wolfgang Amadeus Mozart, primera gran ópera cantanda en alemán y estrenada en Viena el 16 de julio de 1782, en el antiguo Burgtheater, que con gran satisfacción de Mozart alcanzaría un notable éxito popular ${ }^{16}$.

Para esa época, el espíritu de la Ilustración se había consolidado, no sólo con la publicación paulatina del celebérrimo Dictionaire raisonné des sciences, des arts et des métiers (1751-1780), empujado por figuras tan señeras como Diderot, Montesquieu, Rousseau, Marmontel y otros, sino también con la difusión de libros tan decisivos como el Candide de Voltaire (1759) y el $\mathrm{Du}$ Contrat social ou principes $d u$ droit politique, de Jean-Jacques Rousseau (1762) entre muchos otros. Igualmente, el nuevo espíritu animaba la renovación de la ciencia y de la visión del mundo y 
los seres humanos, con la apertura de pensamiento que Montesquieu había propuesto en su Discours sur les motifs qui doivent nous encourager aux sciences (1725), apostando por escribir con buen estilo tratados ambiciosos pero comprensibles para todos ${ }^{17}$. Y como no podía ser menos, aquel tono cultural iba a dominar también las intenciones de una nueva generación de viajes y viajeros a Oriente, que en la segunda mitad del siglo XVIII volverían a llevarse a cabo.

Hasta la Revolución Francesa de 1789, el espíritu reformista brilló en Europa, apoyado por monarcas como Federico II de Prusia (1740-1786), José II de Austria (1780-1790), Catalina II de Rusia (1762-1796) y Carlos III de España (1759-1788), pero también por otras coronas y países menores, como Dinamarca. Precisamente de este país y como iniciativa personal de su rey Federico V, en 1761 salió una expedición a Oriente, de la que volvería seis años después un solo superviviente, el geógrafo y astrónomo Carsten Niebuhr. Navegaron primero de Copenhague a Constantinopla y Alejandría, visitaron Egipto, el Mar Rojo y el Yemen y algo de Arabia, partiendo luego hacia la India. Poco a poco fueron muriendo todos a causa de distintas enfermedades, salvándose únicamente Niebuhr, que desde Bombay emprendería en solitario el viaje de retorno por Irán, Mesopotamia y Turquía. Una vez en Copenhague publicó los resultados del viaje en varios libros ${ }^{18}$, de los que pronto seguirían ediciones en ditintos países europeos. Sus escritos son los propios de un ilustrado. Revelan una enorme curiosidad por todo -geografía, arquelogía, etnología-, y la confianza en la seguridad que aporta la ciencia y la experiencia personal rigen sus reflexiones y sus comentarios. Además, el tono agradable responde a lo que Montesquieu deseaba para cualquier tratado. Y por si fuera poco, Niebuhr merece un primer puesto en la historia del redescubrimiento del Oriente antiguo, ya que sus cuidadosas copias de inscripciones, tomadas en Persépolis, permitirían a Georg Friedrich Grotefend realizar en el primer descifre de la escritura cuneiforme. Como muestra del espíritu de la época que le animó, su hijo dejaría escrito que "rmi padre fue creado única y exclusivamente para examinar y observar el universo, ...vivía para estudiar y comprender las cosas que le rodeaban» ${ }^{19}$.

A comienzos de los años ochenta, Francia parecía resuelta a profundizar su tradicional influencia en Turquía, renovando sus embajadas y destacando consulados en partes remotas. En 1784, la embajada del conde de Choiseul-Goffier decidiría el viaje del artista Louis-François Cassas, autor de tantas y tan magníficas acuarelas, lienzos, dibujos y láminas sobre el Oriente de su época o las ruinas del antiguo ${ }^{20}$. Y en aquellos años también, en la remota Bagdad compartían aficiones y curiosidades 
los miembros de una interesante colonia francesa, agrupada en torno al cónsul general Jean-François Rousseau ${ }^{21}$, de la que formaban parte el abate Joseph de Beauchamp y el botánico André Michaux, ambos ligados a la historia de la ciencia sobre el Oriente antiguo. El primero, por sus estudios in situ sobre las monumentales ruinas del palacio sasánida de Ctesifonte, sus "sondeos» en las ruinas de Babilonia, sus artículos del Journal des Savants y su correspondencia con el también abate Barthélemy: el segundo, por el famosísimo kudurru casita que lleva su nombre, primer gran monumento de la antigüedad oriental que ingresó en las colecciones francesas ${ }^{22}$.

Por lo que hace a España, tras los primeros reinados borbónicos, dedicados sobre todo a implantar una nueva administración y distintos usos, el reinado de Carlos III (1759-1788) supuso la reanudación de la proyección exterior. Como siempre, América y el Pacífico recogieron la mayor parte de los viajes y expediciones científicas o de reconocimiento ${ }^{23}$, y la cartografía marítima contribuiría con obras excelentes a la general reactivación científica, como sugiere el famoso Atlas de Tofiño ${ }^{24}$. Oriente no parece haber atraído especialmente la curiosidad de la época, pero razones políticas decidieron el envío de dos embajadas a Constantinpla, encabezadas ambas por sendos y excelentes marinos, Gabriel de Aristizábal y Federico Gravina. La primera era portadora de regalos, y sancionaba la paz firmada en 1782 . La segunda se habilitó en 1788 para llevar al embajador turco en su viaje de vuelta a Turquía. Un libro magnífico, publicado por Don José Moreno en 1790 y titulado Viaje a Constantinopla en el año 1784, difundiría la descripción del imperio, sus costumbres, instituciones y monumentos entre los españoles; del segundo, Gravina y sus oficiales redactarían sendos informes que no verían la luz entonces, pero que son de una amenidad e intéres excepcional, pudiendo contarse entre las buenas aportaciones de la literatura española de viajes a Oriente. Lejos estaba Gravina entonces de imaginar que pocos años después, el destino la tenía reservado unir su nombre al desastre de aquella magnífica marina ilustrada en Trafalgar ${ }^{25}$.

Pero el siglo de la Ilustración iba a acabar antes de que lo hiciera en el calendario. En 1789 estalló en Francia la revolución burguesa y popular que liquidaría el Antiguo Régimen, uno los hechos mas trascendentales de la Historia. Sus efectos se harían sentir en lo profundo del pensamiento humano, la cultura y la ciencia. E incluso en la pequeña historia del viaje a Oriente. Cinco años después de que Gravina anclara su nave en Constantinopla, llegaba a la ciudad el navío de GuillaumeAntoine Olivier, naturalista y enviado de la República a Irán. A la vuel- 
ta preparía un libro de gran interés ${ }^{26}$, pero quiso la fortuna que la expedición napoleónica a Egipto y la monumental publicación de sus resultados oscureciera las aportaciones de Olivier. Y es que otros sentimientos y otros objetivos se estaban ya perfilando en el horizonte.

\section{Notas}

1 La primera edición holandesa (1711) de mil ejemplares, publicada en Amsterdam, que se titulaba Reizen over Moskovie, door Persie en Indie, fue dedicada al Duque de Brunswick-Lunenbourg y se agotó pronto. En 1714 se hizo una nueva tirada, y cuatro años después, también en Amsterdam, se publicó una versión francesa. En 1720 se editó en Londrés la traducción inglesa, y ya en Francia se llevarían a cabo otras ediciones. Sobre la obra y el viaje véase, DRIJVERS, J. W. (1991): «Cornelis de Bruijn and Gijsbert Cuper. A skilled artist and learned discussion", en SANCISI-WEERDENBURG, H. y DRIJVERS, J. W. (eds.): Through Travellers' Eyes. European Travellers on the Iranian Monuments. Nederlands Istittuut Voor het Nabije Oosten, Leiden, pp.89-107.

2 DRIJVERS, J. W. (1991): op. cit., p. 92.

3 SYNDRAM, K. U. (1989): «Der erfundene Orient und der europäischen Literatur vom 18. bis zum Beginn des 20. Jahrhunderts», en SiEvernich, G. y BuDDE, H. (eds.): Europa und der Orient, 800-1900. Bertelsmann Lexikon Verlag, Berlin, pp.324-341.

4 Se ha dado en llamar así a una serie de artistas europeos instalados en Istanbul, que pintaron sus lienzos al servicio de la comunidad europea principalmente, y que repartidos luego por Europa, ayudaron a popularizar las ropas y tipos propios de Turquía. Véase BopPE, A. (1989): Les peintres du Bosphore au dix-huitème siècle, ACR Édition Internationale, Courbevoie (Paris). Sobre Jean-Baptiste van Mour véase también, SiEverNICH, G. y BUDDE, H. (eds.) (1989): op. cit., pp. 832-833.

5 PAPE, M. E. (1989): «Turquerie im 18. Jahrhundert und der Recueil Ferriol», en SIEVERNICH, G. y BUDDE, H. (eds.) (1989): op. cit., pp. 305-323.

${ }^{6}$ Conservado hoy en la National Portrait Gallery de Londres, el lienzo representa a la esposa del embajador vestida con un lujo suntuoso, paseando de la mano a su pequeño de cuatro años todavía, dentro de un interior decorado a la turca, abierto a un exterior en cuyo fondo parece distinguirse Istanbul. Lady Mary está flanqueda por dos servidores turcos, una muchacha sentada que tañe un instrumento de cuerda, y una especie de mensajero que se acerca a ofrecerle una carta. Representación y comentarios al cuadro en SiEVERNICH, G. y BUDDE, H. (eds.) (1989): op. cit., pp. 816-817.

7 Como se dice en la versión española, las cartas de Lady Mary no son comparables a otros ejemplos de la literatura de viajes, los detalles fallan bastante y la geografía es limitada. Pero su visión femenina es capaz de entrar en temas y ambientes a los que nadie antes había accedido, y en su conjunto son documentos francamente interesantes. FILIPETTO, C. y PALlejá DE Bustinza, V. (eds.) (1998): Cartas desde Estambul de Lady Mary Wortley Montagu. Editorial Casiopea, S. L., Barcelona 1998. Incluye un prólogo de Hugh Thomas.

8 Una excelente versión española en, MonTESqUiEU (1997): Cartas persas. Edición de F J. Hernández. Ediciones Cátedra, S. A., Madrid. 


\section{En el espíritu de la ilustración}

9 Magníficos los comentarios y análisis de Edgar Mass en su capitulo «La crítica política del literato Charles de Montesquieu», en STACKELBERG, J. (dir.) (1984): Literatura Universal. Tomo 13. Ilustración europea, III. Editorial Gredos, S. A., Madrid, pp. 117136.

10 Hernández, Fco. J. en su edición de Montesquieu (1997): op. cit., p. 29.

11 PAPE, M. E. (1989): op. cit., pp. 309-315. Y también, en el mismo libro editado por SiEVERNICH, G. y BuDdE, H., véanse pp. 819-820.

12 PAPE, M. E. (1989): op. cit., p. 318.

13 Menzhausen, I. (1988): Alt-Meissner Porzellan in Dresden. Hoffmann \& Campe Verlag, Berlin, pp. 18-21 y láminas 129-130. También, PAPE, M. E. (1989): op. cit., pp.318-319. En la misma obra, editada por SIEvERNICH, G. y BUDDE, H., véanse fichas e ilustraciones en pp. 790-793.

14 STACKelberg, J. V. (1984): «Voltaire: ilustrado, clasicista y pionero de la anglofilia en Francia", en StACKelberG, J. (dir.), op. cit., pp. 137-174. Vid. p. 172.

15 Para una aproximación al tema turco en la escena musical europea y una síntesis de contenidos, intenciones y modelos - como la supuesta inspiración en la persona del reformista emperador José II para la figura del comprensivo pachá Selim- véase BATTA, A. y NEEF, S. (eds.) (1999): Ópera. Compositores, obras, intérpretes. Könemann Verlagsgesellchaft mbH, Colonia, pp. 356-361 y especialmente, p. 356.

16 Massin, J. y B. (1987): Wolfgang Amadeus Mozart. Ediciones Turner, S. A., Madrid, pp. 517, 520 y 1104-1120.

17 MASs, E. (1984): op. cit., p. 130.

18 Las ediciones clásicas son las siguientes: Beschreibung von Arabien aus eigenen Beobachtungen und im Land selbst gesammelten Nachrichten abgefasset. Nicolaus Möller, Copenhagen 1772: Description de l'Arabie d'apres les Observations et recherches faites dans le Pays Meme. Dos volúmenes publicados en la imprenta de Nicolaus Möller, Copenhagen 1774 y 1778, y un tercer volumen mucho después en Hamburg (1837).

19 Hansen, Th. (1981): La mort en Arabie. Lausanne, p. 308.

20 Gilet, A. (1989): «Louis François Cassas und der Orient», en Sievernich, G. y BuDdE, op. cit., pp. 279-287.

21 El cónsul Rousseu es uno de los personajes más interesantes de todos lo que durante aquellos años se movieron por Oriente. En 1787 informó a su ministro, que el cirujano Outrey había descubierto cerca de Hilla, unas enormes ruinas en las que encontró ladrillos con inscripciones semejantes a las halladas en Persépolis. Se trataba obviamente de Babilonia. Véase, DeHÉRAIN, H. (1938): «Jean François Rousseau, agent de la Compagnie des Indes, consul et orientaliste (1738-1808)", en su libro: Silvestre de Sacy (17581838). Ses contemporains et ses disciples. Librairie Orientaliste Paul Geuthner, Paris, pp. 25-40.

22 Parrot, A. (1946): Archéologie mésopotamienne. Les étapes. Éditions Albin Michel, Paris. Sobre la comunidad de Bagdad, Beauchamp y Michaux véanse pp. 17-22.

${ }^{23}$ Entre 1767 y 1792 se cuentan 37 grandes expediciones por el Pacífico Sur, Norte y Filipinas, con objetivos geoestratégicos y científicos muy variados. Así BAÑAS LLANOS, B. (1992): «Expediciones científicas españolas al Pacífico, en la segunda mitad del siglo XVIII", Revista Española del Pacífico, 2, pp. 85-108. También hay que destacar los trabajos de MELlén Blanco, Fco. "El virrey Amat y la expedición a la Isla de Pascua», PALAU BAquero, M. y Zabala Mouriz, A. «Expediciones españolas a Tahití» e Higueras RoDRíGUEZ, D. "La expedición Malaspina, 1789-1794», publicados en MARTínez SHAW, C. (ed.) (1988): El Pacífico español. Ministerio de Asuntos Exteriores, Madrid, pp. 107-119, 


\section{Joaquín $M^{a}$ Córdoba}

121-11 y 147-163 respectivamente. Y naturalmente, la obra de SÁIZ, B. (ed.) (1994): Alejandro Malaspina. La América imposible. Compañía Literaria, Madrid.

${ }^{24}$ López PIÑERo, J. M . (1988): "Impulso y desarrollo de la actividad científica», en IGLESIAS, $\mathbf{M}^{a}$. C. (ed.): Carlos III y la Ilustración. Ministerio de Cultura, Madrid, pp. 265268. Sobre el atlas de Tofiño en concreto, vid. p. 268 así como su ficha en p. 688.

25 Recientemente, una corriente arrastrada por el éxito de la novela de Arturo PérezReverte, titulada Cabo Tafalgar (Alfaguara, Santillana Ediciones Generales, S. L., Madrid 2004), trasladada a artículos de opinión y a todo cuanto hoy crea la llamada «opinión pública», ha convertido a Federico Gravina en el responsable directo de la catástrofe española, por no haberse opuesto a la decisión del almirante Villeneuve. No obstante, los verdaderos estudios sobre el tema destacan por el contrario su tenaz oposición y su lucha contra el tiempo, aunque a la postre no le cupiera más que aceptar las órdenes que también lo eran de su gobierno en Madrid. Para una pormenorizada exposición de los hechos y la domentacion véase, CAYuela Fernández, J. y Pozuelo Reina, Á. (2004): Trafalgar. Hombres y naves entre dos épocas. Editorial Ariel, S. A., Barcelona 2004, pp. 275-291.

26 BERNARD, P. (1997): «Le Voyage dans l'Empire Othoman, l'Égypte et la Perse, de Guillaume-Antoine Olivier, naturaliste et envoyé de la République (1792-1798)», Comptes Rendus de l'Accadémie des Inscriptions, fascicule IV, pp. 1157-1244. 